\title{
Prevalence and characteristics of polycystic ovarian syndrome in women attending in outpatient department of obstetrics and gynecology of Bangabandhu Sheikh Mujib Medical University, Dhaka, Bangladesh
}

\section{Kaniz Fatema*, Tripti Rani Das, Rezaul Karim Kazal, Sharmeen Mahamood, Hasna Hena Pervin, Farah Noor, Bidisha Chakma}

Department of Obstetrics and Gynecology, Bangabandhu Sheikh Mujib Medical University, Dhaka, Bangladesh

Received: 02 January 2021

Accepted: 30 January 2021

\author{
*Correspondence: \\ Dr. Kaniz Fatema, \\ E-mail: dr.kfzaman@yahoo.com
}

Copyright: (C) the author(s), publisher and licensee Medip Academy. This is an open-access article distributed under the terms of the Creative Commons Attribution Non-Commercial License, which permits unrestricted non-commercial use, distribution, and reproduction in any medium, provided the original work is properly cited.

\begin{abstract}
Background: Polycystic ovary syndrome (PCOS) is a heterogenous, multifactorial, complex genetic disorder. Most commonly, it affects the females of reproductive age. This is one of the most widespread diseases across the world and if left untreated, may result in infertility and even uterine cancer.

Methods: A cross sectional observation study of 100 PCOS patients was carried out from August 2018 to July 2019 in gynecology out-patient department of Bangabandhu Sheikh Mujib medical university, Dhaka. In this study clinical, biochemical and hormonal profile of these patients were analyzed and correlation was done between clinical features and biochemical and hormonal profile.

Results: The prevalence of PCOS was $6.11 \%$ in the gynecology out-patient visits and $35.39 \%$ among infertile

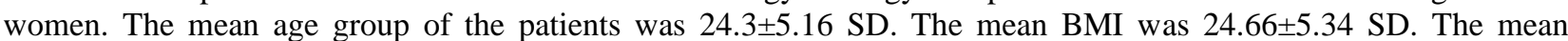
duration of infertility was 5.17 years. The prevalence of metabolic syndrome in our study was $15.0 \%$. In this study menstrual irregularity was the most common complaint. Spearman's correlation between various clinical and laboratory parameters showed positive correlation exists between BMI and testosterone $(r=0.4824 ; \mathrm{p}<0.0001)$.

Conclusions: The study showed that most of our polycystic ovary syndrome subjects were present with oligomenorrhea. Hirsutism and central obesity were also common presentation. Obese women with PCOS had more severe ovulatory dysfunction and need more attention for their appropriate management.
\end{abstract}

Keywords: Body mass index, Hirsutism, Obese, Polycystic ovary syndrome

\section{INTRODUCTION}

Polycystic ovary syndrome (PCOS) is a hormonal disorder, very common in women of reproductive age. Many investigators have shown that lean women with PCOS have insulin resistance and that overweight PCOS subjects are more severely affected that those of the same BMI without PCOS. ${ }^{1}$ The increasing average BMI and propensity to central adiposity are strongly correlated with risk factors for type 2 diabetes mellitus, osteoarthritis, cardiovascular disease, sleep apnea, breast and uterine cancer and disorders of the reproductive system. ${ }^{1,2}$ Subjects who are overweight with PCOS are less likely to achieve pregnancy spontaneously or with medical assistance. ${ }^{3}$ Treatment of PCOS must focus both on normalizing of hyper and rogenism and anovulation. Reducing metabolic complications is the key significance in the prevention and treatment of impaired glucose tolerance (IGT) and type 2 diabetes mellitus. This can be achieved through pharmacological intervention or preferably lifestyle modification. Total weight loss and loss of a crucial amount of abdominal fat are important treatment strategies. Reproductive and metabolic benefits resulting from weight loss are result from a reduction in 
circulating insulin. Initial use of insulin-sensitizing drugs, including metformin and the thiazolidinedione, has promising metabolic and clinical results. ${ }^{4}$ The beneficial effects of weight loss on the clinical and bio-chemical manifestations of PCOS have also been consistently documented. ${ }^{5}$ Short term weight loss intervention studies (four to eight weeks) have decreased abdominal fat. In spite of the effectiveness of short-term weight loss resulting from moderate or severe caloric restriction, sustained long term weight loss is unlikely. Once weight is regained, the manifestation of PCOS and associated long term morbidity and mortality risks will probably return. The NIH guideline for the long-term treatment of overweight and obesity emphasize the importance of achievable and sustainable goals, notably a combination of diet modification, physical activity and behavior therapy. ${ }^{6}$ These principals are consistent with those examined over the long term in the diabetic population. A systematic review and meta-analysis done by Liza Haqq, James McFarlane et all of the University of New England shows that, lifestyle (diet and exercise) intervention improves the levels of FSH, SHBG, total testosterone, and rostenedione level. Exercise alone improved all of these outcomes except LH. Lifestyle intervention or exercise alone showed a significantly favorable improvement in hirsutism. These findings support those of previous work suggesting that lifestyle intervention and exercise improve hirsutism. ${ }^{7}$ Anovulation is the main cause of infertility in women with PCOS. Many regimens have been evolved to induce ovulation. In recent years, there has been increasing evidence that hyper secretion of LH is deleterious both to fertility and to pregnancy outcome. Polycystic ovary syndrome is the most common cause of anovulatory infertility. Increased BMI and age can also contribute to infertility, and woman should be counselled about the importance of maintaining a healthy weight $\left(\mathrm{BMI}<30 \mathrm{~kg} / \mathrm{m}^{2}\right)$ and optimal timing of family initiation. ${ }^{8}$ Fertility of woman declines significantly with a BMI $>30-32 \mathrm{~kg} / \mathrm{m}^{2}$. An intensive lifestyle program addressing weight loss without any pharmacological treatment for the first 6 month, is recommended. ${ }^{8}$ Women with PCOS are a subset of the population that would probably benefit greatly from routine exercise. Exercise increases insulin sensitivity both by acting directly on muscle metabolism and indirectly by assisting in weight management. ${ }^{9}$ Furthermore beneficial effects of exercise might not be reflected in a substantial change in body weight or apparent body shape. It is important to emphasize that significant benefits can be gained with only modest changes in energy expenditure or weight reduction. ${ }^{10}$ Estimations of the prevalence of PCOS depend on the population being assessed, as there are ethnic differences in the clinical and biochemical features of PCOS. ${ }^{11}$ The prevalence of PCOS can be as high as $30 \%$ in women with secondary amenorrhea, $40 \%$ in women with infertility, $75 \%$ in women with oligomenorrhea and $90 \%$ in women with hirsutism. ${ }^{12}$ PCOS IS a common endocrine disorder encountered by the clinician in women of reproductive age affecting $5 \%$ to $10 \%$ of the general population. ${ }^{13}$

\section{METHODS}

This prospective cross-sectional study was conducted at department of obstetrics and gynecology, Banga Bandhu Sheikh Mujib medical university, Dhaka, Bangladesh from August 2018 to July 2019. The study was approved by ethical review committee, BSMMU Dhaka, Bangladesh. According to statistical calculation a total of 100 PCOS patients were selected as study population following selection criteria. Women who were diagnosed as PCOS in reproductive age (15-35) group attended at the gynecology OPD of BSMMU were enrolled in this study. Sample was selected by consecutive, convenient sampling technique. Normal females without PCOS, pregnant, age $>35$ or $<15$, patients with symptomatic diseases (liver, kidney, heart or other symptomatic diseases) were excluded from study. Informed written consent was taken from each participant prior to enrollment in study. All study participants were evaluated by history, clinical examination and investigation. Data analysis done by SPSS software.

\section{RESULTS}

A total of 3832 patients visited gynecology out patient department between August 2018 to July 2019 and 100 patients were found to have newly detected PCOS. The prevalence of PCOS was $6.11 \%$ in general gynecological OP visits. Similarly, in patients attending infertility OPD during the study period, there were 56 new cases and 196 old cases, making the prevalence in the infertile population $35.39 \%$ among 712 total visits.

Table 1: Socio-demographic characteristics of the study population $(n=100)$.

\begin{tabular}{|lll|}
\hline Variables & N & Percentage (\%) \\
\hline Age group (years) & & \\
\hline 15 to 20 & 24 & 24.0 \\
\hline 21 to 25 & 47 & 47.0 \\
\hline 26 to 30 & 13 & 13.0 \\
\hline 31 to 35 & 16 & 16.0 \\
\hline Religion & & \\
\hline Muslim & 91 & 91.0 \\
\hline Hindu & 07 & 07.0 \\
\hline Christian & 02 & 02.0 \\
\hline Education & & \\
\hline Degree & 35 & 35.0 \\
\hline High School & 45 & 45.0 \\
\hline Primary School & 20 & 20.0 \\
\hline Socio economic status & & \\
\hline Lower & 17 & 17.0 \\
\hline Middle & 75 & 75.0 \\
\hline Upper & 08 & 08.0 \\
\hline Body mass index (kg/m & & \\
\hline$<18.5$ (underweight) & 12 & 12.0 \\
\hline 18.5-24.9 (normal) & 31 & 31.0 \\
\hline 25-29.9 (overweight) & 41 & 41.0 \\
\hline $30-34.9$ (obese) & 14 & 14.0 \\
\hline$\geq 35$ (morbid obese) & 02 & 02.0 \\
\hline & & \\
\hline
\end{tabular}


Table 2: Clinical profile of 100 PCOS patients $(\mathrm{n}=\mathbf{1 0 0})$.

\begin{tabular}{|lrr|}
\hline Variables & N & $\%$ \\
\hline Sign of hyperandrogenism & \multicolumn{1}{l|}{} \\
\hline Hirsutism & 80 & 80.0 \\
\hline Acne & 25 & 25.0 \\
\hline Acanthosis nigricans & 15 & 15.0 \\
\hline Androgenic alopecia & 05 & 05.0 \\
\hline Waist circumference (WC) (cm) & & \\
\hline$\leq 88$ & 65 & 65.0 \\
\hline$>88$ & 35 & 35.0 \\
\hline Waist hip ratio (WHR) & & \\
\hline$<0.8$ & 67 & 67.0 \\
\hline$\geq 0.8$ & 33 & 33.0 \\
\hline Manifestations of ovarian dysfunction & \\
\hline Oligomenorrhea & 56 & 56.0 \\
\hline Secondary amenorrhea & 04 & 04.0 \\
\hline Ultrasound polycystic ovaries & 95 & 95.0 \\
\hline Associated conditions blood pressure (mmHg) \\
\hline$<130 / 85$ & 81 \\
\hline$\geq 130 / 85$ & 81.0 \\
\hline Dyslipidemia (mg/d) & 19 & 19.0 \\
\hline Total cholesterol $\geq 200$ & & \\
\hline HDL <50 & 16 & 16.0 \\
\hline TG >150 & 12 & 12.0 \\
\hline Metabolic syndrome & 12 & 12.0 \\
\hline Diabetes mellitus & 15 & 15.0 \\
\hline Impaired blood sugars & 10 & 10.0 \\
\hline & 25 & 25.0 \\
\hline
\end{tabular}

Table 1 shows the demographic profile of PCOS patients. Mean age of the patients was $24.3 \pm 5.16$ and majority of the patients belonged to the age group between 21-25 years $(47 \%)$. The mean BMI was $24.66 \pm 5.34$ where $41 \%$ were overweight and $91 \%$ of the patients were Muslim.
Table 2 shows clinical profile of 100 PCOS patients. About all were detected to have PCOS in ultrasonography. FLP was done of all patients. In our study among 100 PCOS patients, hirsutism was present in $80 \%$. Androgenic features like acne were present in $25 \%$ of the patients, acanthosis nigricans in $15 \%$ of the patients and androgenic alopecia was present in $5 \%$.

Table 3: Hormonal profile of study population $(n=100)$.

\begin{tabular}{|c|c|c|c|c|}
\hline Investigations & Values & $\mathbf{N}$ & $\%$ & Mean \pm SD \\
\hline \multirow{3}{*}{ TSH (mIU/I) } & $<0.27$ & 02 & 02.0 & \multirow{3}{*}{$\begin{array}{l}3.13 \pm \\
1.32\end{array}$} \\
\hline & $\begin{array}{l}0.27- \\
4.2\end{array}$ & 79 & 79.0 & \\
\hline & $>4.2$ & 19 & 19.0 & \\
\hline LH (mIU/I) & $>12$ & 27 & 27.0 & $\begin{array}{l}10.33 \pm \\
2.48\end{array}$ \\
\hline \multirow{2}{*}{$\begin{array}{l}\text { Prolactin } \\
(\mathrm{ng} / \mathrm{ml})\end{array}$} & $<25$ & 85 & 85.0 & $19.64 \pm$ \\
\hline & $>25$ & 15 & 15.0 & 5.58 \\
\hline \multirow{2}{*}{$\begin{array}{l}\text { LH/FSH } \\
\text { (IU/I) }\end{array}$} & $<2: 1$ & 63 & 63.0 & $2.31 \pm$ \\
\hline & $>2: 1$ & 37 & 37.0 & 1.20 \\
\hline \multirow{2}{*}{$\begin{array}{l}\text { Testosterone } \\
(\mathrm{ng} / \mathrm{ml})\end{array}$} & $<0.8$ & 51 & 51.0 & $0.804 \pm$ \\
\hline & $\geq 0.8$ & 49 & 49.0 & 0.076 \\
\hline
\end{tabular}

Table 3 shows biochemical and hormonal profile of PCOS patients. Metabolic syndrome diagnosis was made according to NCEP ATP 3 criteria. The prevalence of metabolic syndrome was calculated and it is found to be $15.0 \%$.

Table 4 shows Spearman's correlation between the different clinical features and laboratory parameter. The following association appears.

Table 4: Spearman's correlation between the different clinical features and laboratory parameter.

\begin{tabular}{|c|c|c|c|c|c|c|c|}
\hline Correlations & & BMI & WHR & Weight & LH & FSH & Prolactin Testosterone \\
\hline \multirow{3}{*}{ BMI } & Correlation coefficient & 1 & & & & & \\
\hline & $\mathrm{P}$ value & 0 & & & & & \\
\hline & $\mathrm{N}$ & 100 & & & & & \\
\hline \multirow{3}{*}{ WHR } & Correlation coefficient & $0.6327 *$ & 1 & & & & \\
\hline & $\mathrm{P}$ value & 0 & & & & & \\
\hline & $\mathrm{N}$ & 100 & 100 & & & & \\
\hline \multirow{3}{*}{ Weight } & Correlation coefficient & $0.6542 *$ & $0.4244 *$ & 1 & & & \\
\hline & $\mathrm{P}$ value & 0 & 0 & & & & \\
\hline & $\mathrm{N}$ & 100 & 100 & 100 & & & \\
\hline \multirow{3}{*}{$\mathbf{L H}$} & Correlation coefficient & -0.0255 & 0.1474 & 0.138 & 1 & & \\
\hline & $P$ value & 0.801 & 0.1434 & 0.171 & & & \\
\hline & $\mathrm{N}$ & 100 & 100 & 100 & 100 & & \\
\hline \multirow{3}{*}{ FSH } & Correlation coefficient & 0.0531 & 0.0617 & 0.0998 & $-0.2686^{*}$ & 1 & \\
\hline & $\mathrm{P}$ value & 0.5995 & 0.5419 & 0.3232 & 0.0069 & & \\
\hline & $\mathrm{N}$ & 100 & 100 & 100 & 100 & 100 & \\
\hline \multirow{3}{*}{ Prolactin } & Correlation coefficient & -0.1328 & -0.0656 & -0.0775 & $0.2063^{*}$ & $\begin{array}{l}- \\
0.1047\end{array}$ & 1 \\
\hline & $\mathrm{P}$ value & 0.1879 & 0.5165 & 0.4434 & 0.0395 & 0.2997 & \\
\hline & $\mathrm{N}$ & 100 & 100 & 100 & 100 & 100 & 100 \\
\hline
\end{tabular}




\begin{tabular}{|lllllllll|}
\hline Correlations & & BMI & WHR & Weight & LH & FSH & Prolactin & Testosterone \\
\hline \multirow{2}{*}{$\begin{array}{l}\text { Testostero } \\
\text { ne }\end{array}$} & Correlation coefficient & $0.4824^{*}$ & $0.3482^{*}$ & $0.4735^{*}$ & -0.0025 & 0.0537 & 0.0672 & 1 \\
\cline { 2 - 8 } & P value & 0 & 0.0004 & 0 & 0.9802 & 0.5954 & 0.5063 & \\
\cline { 2 - 7 } & $\mathrm{N}$ & 100 & 100 & 100 & 100 & 100 & 100 & 100 \\
\hline
\end{tabular}

Table 5: Marital and infertility status of study population $(n=100)$.

\begin{tabular}{|lcc|}
\hline Characteristics & N & $\%$ \\
\hline Marital history & & \\
\hline Married & 75 & 75.0 \\
\hline Unmarried & 25 & 25.0 \\
\hline Fertility status & & \\
\hline Parous & 20 & 20.0 \\
\hline Nulliparous & 55 & 55.0 \\
\hline Type of infertility & & \\
\hline Primary infertility & 48 & 48.0 \\
\hline Secondary infertility & 08 & 08.0 \\
\hline Duration of infertility & (year) & \\
\hline $01-04$ & 18 & 18.0 \\
\hline $05-08$ & 20 & 20.0 \\
\hline $09-12$ & 04 & 04.0 \\
\hline
\end{tabular}

Table 5 shows the marital and parity status of patients. In our study among 100 PCOS patients, $75 \%$ were married and $25 \%$ were unmarried. Among married women about $26.57 \%$ parous and $73.33 \%$ were nulliparous. About eighty-six $(86 \%)$ patients presented with primary infertility and $14 \%$ with secondary infertility. The mean duration of infertility was 5.17 years.

Table 6: Univariate logistic regression analysis predicting the metabolic syndrome.

\begin{tabular}{|lllll|} 
Variables & $\mathbf{P}$ & $\begin{array}{l}\text { Odds } \\
\text { ratio }\end{array}$ & $\begin{array}{l}\text { 95\% C.I. for odds } \\
\text { ratio }\end{array}$ \\
\hline Weight & 0.98 & 0.9990675 & 0.9275503 & 1.076099 \\
\hline Age & 0.26 & 0.9352166 & 0.8306415 & 1.052957 \\
\hline BMI & 0.60 & 0.9732365 & 0.8783813 & 1.078335 \\
\hline WHR & 0.15 & 0.0003985 & $8.54 \mathrm{e}-09$ & 18.58239 \\
\hline TSH & 0.03 & 0.6306995 & 0.4137549 & 0.961395 \\
\hline Constant & 0.00 & 0.000 & & \\
\hline
\end{tabular}

Table 6 shows univariate logistic regression analysis is used to find out the predictor for the metabolic syndrome, it showed TSH is the variable which has 0.63 times risk for metabolic syndrome and this is significant with the $\mathrm{p}$ value of 0.032 and $95 \%$ confidence interval is $(0.4137549,0.961395)$.

\section{DISCUSSION}

The prevalence of PCOS using Rotterdam criteria in our study was $6.11 \%$ among gynecological out-patient visits. In different parts of India like Andhra Pradesh prevalence of PCOS among adolescents is $9.13 \% .^{14}$ In Lucknow,
U.P., India $3.7 \%$ females $18-25$ years of age are found to have PCOS. ${ }^{15}$ In a study conducted on 27,411 samples by Metropolis healthcare Ltd. $17.6 \%(4,825)$ are found to have PCOS. The regional distribution of prevalence of PCOS is found to be $18.62 \%$ in North India, $25.88 \%$ in East India, $19.88 \%$ in West India, and $18 \%$ in South India. Thus, PCOS affects every fifth Indian female. ${ }^{16}$ In the neighboring countries like Pakistan, around $21.9 \%$ females are infertile of the total population, among which $38.5 \%$ of the infertility is due to PCOS. ${ }^{17}$ Another study conducted in the Aga Khan university hospital, and concept fertility center, Karachi, Pakistan, from January 2003 till December 2004, a total of 508 were checked for the symptoms of PCOS. Among them $17.6 \%$ were found to have PCOS. ${ }^{18}$ In Bangladesh, a study was conducted on 16700 infertile females among which $31.7 \%$ of the female population is suffering from PCOS. ${ }^{19}$ Just like Pakistan and Bangladesh, Nepal's female population has been suffering from PCOS. About $5-10 \%$ of the total population of Nepal is suffering from PCOS. ${ }^{20}$ The rate of female population having PCOS in Myanmar is 5\%.17 The rate of prevalence of PCOS in Sri Lanka is found to be $6.3 \% .^{21}$ The prevalence of PCOS among infertile women in our study was $35.39 \%$, accounting to one third of the patients. Couzin estimated that $40 \%$ of infertile women have PCOS. ${ }^{22}$ This is comparable to our study. In our study mean age of the patients was 24.3 $\pm 5.16 \mathrm{SD}$ and majority of the patients belonged to the age group between 21-25 years (47\%). A recent assessment of the frequency of PCOS in North India was $3.7 \%$ in women aged between 18 and 25 years. ${ }^{23}$ In a study done by Muralidhara et al in KMC Mangalore in 2012 mean age among PCOS patients was $27 \pm 7.1 .^{24}$ A recent study among Palestinian subjects aged 18-24 years reported a PCOS prevalence of $7.3 \%{ }^{25}$ The discrepancy between the previous studies regarding the prevalence of PCOS and the data of this study could be attributed to the recruitment process of the study subjects, small sample size, age difference, and/or ethnic background. For example, the age group. In this study sample was narrow, including women aged 15-35 years, while some other studies included women aged 18-45 years to limit the phenomenon of irregular menstrual cycles in early age and premenopausal age. In our study oligomenorrhea is most common presentation. We found $56 \%$ had oligomenorrhea, $37 \%$ had regular cycles and $4 \%$ had secondary amenorrhea. About $37.1 \%$ of infertility patients had oligomenorrhea which was significant in hirsute women $(p<0.001)$. In our study though a greater number of overweight and obese patients had oligomenorrhea, the difference between obese and nonobese was not significant. In a study done by Ramanand et al at Kohlapur, Maharashtra found that oligomenorrhea was present in $65 \%$ patients. ${ }^{26}$ In our study among 100 
PCOS patients, hirsutism was present in $80 \%$. Androgenic features like acne were present in $25 \%$ of the patients, acanthosis nigricans in $15 \%$ of the patients and androgenic alopecia was present in 5\%. Waist circumference was $>88 \mathrm{~cm}$ in $35 \%$ of the patients and WHR $>0.8$ was seen in $33 \%$ of the patients highlighting that Bangladeshis have more central obesity even at low BMI. Blood pressure recording showed $19 \%$ had BP $\geq 130 / 85 \mathrm{~mm}$ of hg. About $25 \%$ had impaired sugars, $10 \%$ were diagnosed to have diabetes. A study conducted in Boston, MA, USA, reported that $7.5 \%$ of PCOS women had type 2 diabetes. ${ }^{27}$ Total cholesterol was $\geq 200 \mathrm{mg} / \mathrm{dl}$ was present in $16 \%$ of the patients, HDL $<50 \mathrm{mg} / \mathrm{dl}$ was seen in $12 \%$ of the patients and $\mathrm{TG}>150 \mathrm{mg} / \mathrm{dl}$ was present in $16 \%$ of cases. Many researchers consider elevated LH: FSH (>2) diagnostic for PCOS. In this study, day 2 hormonals profile the results showed that, $27 \%$ had elevated LH and LH:FSH $(>2)$ was elevated in $37 \%$ of patients and prolactin was high in $15 \%$ of the patients. Elevated LH and elevated LH: FSH was significant in irregular menstrual group. Total testosterone was elevated in $49 \%$ of the patients. We found that, positive correlation exists between BMI and testosterone $(\mathrm{r}=0.4824 ; \mathrm{p}<0.0001)$, and there is also positive correlation exists between WHR and testosterone $(\mathrm{r}=0.3482 ; \mathrm{p}=0.0004)$. Every patient was evaluated for altered sugars and lipid abnormalities. About $11 \%$ had impaired sugars, $10 \%$ were diagnosed to have diabetes. FBS and 2 hours 75 grams GTT was significant in the PCOS group with metabolic syndrome, with irregular cycles, patients with $\mathrm{BMI}>25$. In a study conducted by Muralidhara et al in 86 PCOS patients, they found that $33 \%$ had FBS $>100 \mathrm{mg} \%$ and impaired glucose tolerance was reported by $17 \% .{ }^{24}$ In obese women, excess insulin and androgens may contribute to the development of the PCOS and metabolic syndrome. Univariate logistic regression analysis is used to find out the predictor for the metabolic syndrome, it showed TSH is the variable which has 0.63 times risk for metabolic syndrome and this is significant with the $\mathrm{p}$ value of 0.032 and $95 \%$ confidence interval is $(0.4137549,0.961395)$. The prevalence of metabolic syndrome in our study was $15 \%$. In a study done in 2008 showed that all PCOS subgroups were more associated with metabolic syndrome than the control group $(\mathrm{p}<0.05){ }^{27}$ The android pattern of fat distribution may be the result as well as the cause of hyperandrogenism, setting up a vicious circle of hyperinsulinism, hyperandrogenism, central adiposity and metabolic abnormalities.

In our study $75 \%$ women were married, among them $73.33 \%$ were nulliparous. Moreover, we observed that, among the nulliparous women $85.71 \%$ presented with primary infertility and $14.29 \%$ with secondary infertility.

\section{CONCLUSION}

Oligomenorrhea was the most common presentation. Obese women with PCOS had more severe ovulatory dysfunction and need more attention for their appropriate management.

\section{Recommendations}

Young women who are diagnosed as PCO are at a risk to develop PCOD and long-term sequel such as diabetes, hypertension and infertility. So, they need follow up, additional diagnostic parameters for diagnosis and management. Assays are needed in addition to ultrasonogram for the further evaluation.

Funding: No funding sources

Conflict of interest: None declared

Ethical approval: The study was approved by the Institutional Ethics Committee

\section{REFERENCES}

1. Despres JP, Lemieux I, Prud'homme D. Treatment of obesity: need to focus on high risk abdominally obese patients. Bio Med J. 2001;322:716-20.

2. Zaadstra BM, Seidell JC, Van Noord PA, Te Velde ER, Habbema JD, Vrieswijk B et al. Fat and female fecundity: prospective study of effect of body fat distribution on conception rates. Bio Med J. 1993;306:484-7.

3. Wang JX, Davies M, Norman RJ. Body mass and probability of pregnancy during assisted reproduction treatment: retrospective study. Bio Med J. 2000;321:1320-1.

4. Iuorno MJ, Nestler JE. Insulin-lowering drugs in polycystic ovary syndrome. Obstet Gynecol. Clin. North Am. 2001;28:153-64.

5. Hoeger K. Obesity and weight loss in polycystic ovary syndrome. Obstet Gynecol Clin North Am. 2001;28:85-97.

6. NIH. Clinical guidelines on the identification, evaluation and treatment of overweight and obesity in adults: evidence report. $\mathrm{J}$ Obesity Res. 1998;6:S51-209.

7. Moran LJ, Hutchison Sk, Norman RJ, Teede HJ. Lifestyle changes in women with polycystic ovary syndrome. Cochrane database systemic receives. 2011;CD007506.

8. Teede HJ, Misso Ml, Deeks AA. Assessment and management of polycystic ovary syndrome. summary of an evidence-based guideline. Med $\mathrm{j}$ Aust. 2011;195;565-112.

9. Kovacs G, Wood, C. The current status of polycystic ovary syndrome. Aust. N Z J Obstet Gynaecol. 2001;41:65-8.

10. Huber-Buchholz MM, Carey DG, Norman RJ. Restoration of reproductive potential by lifestyle modification in obese polycystic ovary syndrome: role of insulin sensitivity and luteinizing hormone. J Clin Endocrinol Metab. 1999;84:1470-4.

11. Jones Gl, Palep Singh M, Ledger WL, Balen AH, Jenkinson C, Campbell MJ et al. Do south Asian women with PCOS have poorer health related quality 
of life than Caucasian women with PCOS? A comparative crosssectional study. Health Quallife Outcomes. 2010;20(8):149.

12. Mortension M, Etormann DA, Little John E, Rosenfield RL. Asymptomatic volunteer with a polycystic ovary is a functionally distinct but heterogeneous population. J Clin Endocrinal Metab. 2009; 94(5):1579-86.

13. Escobar-Morreale H, Carmina E, Dewailly D, Gambineri A, Kelestimur F, Moghetti P, et al. Epidemiology, diagnosis and management of hirsutism: a consensus statement by the Androgen Excess and Polycystic Ovary Syndrome Society. Hum Reprod Update. 2012; 19(2):207.

14. Choudhary N, Padmalatha V, Nagarathna R, Ram A. Prevalence of Polycystic Ovarian Syndrome in Indian Adolescents. J Pediatr Adolesc Gynecol. 2011;24(4):223-7.

15. Gill H, Tiwari P, Dabadghao P. Prevalence of polycystic ovary syndrome in young women from North India: A Community-based study. Ind J Endocrinol Metab. 2012;16(2):389-92.

16. Garg MS, A systematic review on the prevalence and management of PCOS through dietary modifications. Int J Home Sci 2018;4(1):236-9.

17. Arain F, Arif N, Halepota H. Frequency and outcome of treatment in polycystic ovaries related infertility Pak J Med Sci. 2015;31(3):694-9.

18. Haq F, Aftab O, Rizvi J. Clinical, biochemical and ultrasonographic features of infertile women with polycystic ovarian syndrome. J Coll Physicians Surg Pak. 2007;17(2):76-80.

19. Fatima P, Ishrat S, Rahman D, Banu J, Deeba F, Begum $N$ et al. Quality and quantity of infertility care in Bangladesh. Mymensingh Med J. 2015;24(1):70-3.

20. Sangraula H, Paudel KR, Sharma M. Dec; Metformin and troglitazone in the treatment of female infertility associated with polycystic ovarian syndrome. J Nepal Med Assoc. 2009;48(176):335-9.

21. Shi Y, Guo M, Yan J, Sun W, Zhang X, Geng L et al. Analysis of clinical characteristics in large-scale
Chinese women with polycystic ovary syndrome. Neuro Endocrinol Lett. 2007;28(6):807-10.

22. Kumarapeli V, SeneviratneRde A, Wijeyaratne CN, Yapa RM, Dodampahala SH. A simple screening approach for assessing community prevalence and 239. International Journal of Home Science phenotype of polycystic ovary syndrome in a semiurban population in Sri Lanka. Am. J Epidemiol. 2008;168(3).

23. Hussein B, Alalaf S. Prevalence and characteristics of polycystic ovarian syndrome in a sample of infertile Kurdish women attending IVF infertility center in maternity teaching hospital of Erbil City. Open J Obstet Gynecol. 2013;10(3):577-85.

24. Wijeyaratne CN, Seneviratne Rde A, Dahanayake S. Phenotype and metabolic profile of South Asian women with polycystic ovary syndrome (PCOS): results of a large database from a specialist Endocrine Clinic. Hum Reprod. 2011;26(1):202-13.

25. Muralidhara KD, Adhikari PM, Muralidhara DV. A study on the clinical, biochemical and hormonal profile of polycystic ovary syndrome patients attending tertiary care hospital. Indian J Basic App Med Res. 2015;4(3):227-36.

26. Musmar S, Afaneh A, Mo'alla H. Epidemiology of polycystic ovary syndrome: a cross sectional study of university students at An-Najah National universityPalestine. Reprod Biol Endocrinol. 2013;11:47.

27. Ramanand SJ, Ramanand JB, Ghongane BB, Patwardhan MH, Patwardhan VM, Ghanghas R et al. Correlation between serum adiponectin and clinical characteristics, biochemical parameters in Indian women 2 with polycystic ovary syndrome. Ind $\mathbf{J}$ Endocr Metab. 2014;18:221-5.

Cite this article as: Fatema K, Das TR, Kazal RK, Mahamood S, Pervin HH, Noor F, et al. Prevalence and characteristics of polycystic ovarian syndrome in women attending in outpatient department of obstetrics and gynecology of Bangabandhu Sheikh Mujib Medical University, Dhaka, Bangladesh. Int J Reprod Contracept Obstet Gynecol 2021;10:830-5. 